\title{
Prótese total articulada de joelho utilizada no tratamento de osteossarcoma apendicular em cão
}

\author{
Total articulated prosthesis for treatment of apendicular osteosarcoma in a dog
}

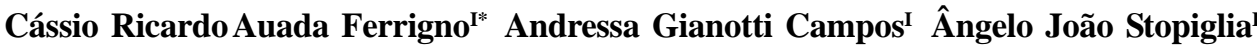 \\ Denise Tabacchi Fantoni ${ }^{\mathrm{I}}$
}

\begin{abstract}
O objetivo do trabalho foi reportar o planejamento cirúrgico, a técnica operatória, a instrumentação e os resultados da substituição completa do terço médio distal do fêmur, do platô tibial e da articulação do joelho por prótese em um cão acometido por osteossarcoma no fêmur esquerdo. A prótese foi confeccionada em aço, apresentando três componentes articulados, mantendo o movimento semelhante à articulação do joelho. As porções femorais e tibiais da prótese foram cimentadas aos respectivos ossos, após ostectomia do fêmur e do platô tibial. O animal foi submetido a seis sessões de quimioterapia, com doxorrubicina e carboplatina, intercaladas mensalmente, objetivando inibir o crescimento de possíveis metástases pulmonares. Durante os seis primeiros dias, o animal apresentou neuropraxia e impotência funcional do membro. Aos 10 dias, o cão iniciou leve apoio e aos 30 dias já utilizava o membro pélvico de forma mais efetiva, porém, o ângulo de extensão da articulação foi reduzido de $150^{\circ}$ a $100^{\circ}$ devido à contratura muscular e à fibrose na região da fossa poplítea. Após um ano de observação, não houve melhora do ângulo de extensão do joelho, porém, o animal fazia uso do membro com claudicação. Aos 425 dias de pós-operatório, o animal veio a óbito por insuficiência renal. Nesse tempo não ocorreram metástases pulmonares ou locais visíveis radiograficamente, mas o proprietário não permitiu a realização da necropsia do paciente, sendo impossível confirmar outros dados que pudessem esclarecer melhor a causa morte. Conclui-se que a substituição total do joelho de cão é uma cirurgia factível, que permite a preservação e a utilização do membro após resseç̧ão da neoplasia, embora outras pesquisas devam ser conduzidas para obtenção de melhores resultados pós-cirúrgicos.
\end{abstract}

- NOTA -
Palavras-chave: cão, joelho, osteossarcoma, prótese.

\begin{abstract}
This report describes the surgical technique, instrumentation and results of complete substitution of portion distal of the femur and knee articulation to prosthesis, in a dog with bone tumor in distal left femur. The prosthesis was made of steel, and composed by three articulated components with the goal of maintaining range of motion as a normal knee movement. The femoral and tibial prosthesis portions were fixed to the respective bones during the surgery, after femural and tibial plato ostectomy. The patient received six doses of adjuvant chemotherapy, composed by doxorrubicin monthly alternated with carboplatin. At six days after surgery the dog developed neuropraxy and non-weight bearing lameness. At 10 days the dog started to mild use of the limb and at 30 days it was more effective, but the extension of the stifle range was reduced by $100^{\circ}$ because of the fibrosis and muscle contracture on the popliteal fossa. At one year, this angle didn't improve but the dog continued to bear weight on the limb. At 425 days, the dog had died by renal failure. At this time, there was no evidence of local recurrence or distant metastasis, but the necropsy was declined by the owner, impairing the collection of more data. In conclusion, the replacement of total knee and half of the femur in dogs is possible and viable, but further study is warranted in order to obtain better technique and specific instrumentation, to attain better surgical outcomes.
\end{abstract}

Key words: dog, knee, osteosarcoma, prosthesis.

O osteossarcoma é o tumor ósseo mais comum nos cães, definido como um tumor mesenquimal maligno de células ósseas primitivas e caracterizado

\footnotetext{
I'Departamento de Cirurgia, Faculdade de Medicina Veterinária e Zootecnia (FMVZ), Universidade de São Paulo (USP). Av. Prof. Dr. Orlando Marques de Paiva, 87, 05508-270, Cidade Universitária, São Paulo, SP, Brasil. E-mail: cassioaf@usp.br. *Autor para correspondência.
} 
pela formação direta de matriz osteóide pelas células tumorais (DERNELL et al., 2001).

Em cães, o tratamento de moléstias que afetam os ossos componentes da articulação do joelho inclui manejo conservativo, artrodese ou amputação, sendo a última mais indicada para tumores ósseos (COFONE et al., 1992). Em humanos, a prótese total de joelho é técnica rotineiramente utilizada não apenas no tratamento de tumores, mas também em outras moléstias (JAIN et al., 2005). A técnica de instalação de próteses de joelho em cães foi documentada com sucesso por TURNER et al.(1989), BERZINS et al.(1994) e SUMNER et al.(1994) de modo experimental, enquanto que LISKA et al. (2007) utilizou prótese em um caso de fratura de côndilo. Entretanto, em nenhuma destas pesquisas foi utilizada prótese em caso clínico de neoplasia óssea.

Assim, a proposta desta nota é relatar a técnica cirúrgica de implantação, a instrumentação e os resultados da substituição da articulação fêmorotibio-patelar em cão com osteossarcoma na região distal de fêmur. Um cão da raça Pastor Alemão, macho, 11 anos de idade, foi atendido no Serviço de Cirurgia de Pequenos Animais da Faculdade de Medicina Veterinária e Zootecnia da Universidade de São Paulo apresentando aumento de volume firme em porção distal de fêmur esquerdo, com sensibilidade à palpação e à claudicação.

O exame radiográfico revelou imagens compatíveis com neoplasia óssea na porção distal do fêmur. O mesmo exame permitiu a mensuração do fêmur e da tíbia em projeções látero-lateral e crânio-caudal, sendo tais dimensões consideradas na confecção do modelo de prótese de aço 316-L. A pesquisa de metástases, por meio de radiografias torácicas e ultrasonografia abdominal, obteve resultado negativo.

Como protocolo anestésico, foram administrados acepromazina, diazepan, propofol e isofluorano. Após tricotomia e anti-sepsia da pele do membro pélvico esquerdo, o campo cirúrgico foi coberto com auto-adesivo estéril impermeável, sendo que o animal permaneceu em decúbito dorsal. Foi realizada incisão lateral iniciando-se em local próximo ao trocanter maior e estendendo-se até $3 \mathrm{~cm}$ abaixo da crista tibial. Na superfície crânio lateral, foram dissecados os músculos vasto lateral, adutor magno e vasto intermédio. Na face caudal do membro, foram individualizados os músculos semi-membranoso, semitendinoso e adutor, juntamente com o nervo isquiático e a plexo femoral, permitindo o acesso ao tumor. Foi realizada a ostectomia em bloco do fêmur, platô tibial e crista da tíbia, com margem de $4 \mathrm{~cm}$ craniais ao tumor na porção femoral.
O canal medular do fêmur teve seu conteúdo removido com auxílio de curetas, preenchido com cimento ósseo cirúrgico (polimetilmetacrilato- Baumer S.A.), permitindo a fixação da haste interna da prótese. O mesmo procedimento foi repetido na porção proximal da tíbia. Após secagem do cimento, os dois componentes da prótese foram unidos por eixo central, permitindo movimentos de flexão e extensão. As fabelas foram recolocadas em sua posição original, fixadas na região distal da prótese por meio de sutura com fio prolene $\mathrm{n}^{\mathrm{0}} 1$. A crista tibial foi fixada com dois fios de Kirschner na porção dorso-cranial da tibial. Após reposicionamento da patela no sulco da prótese, foi realizada a síntese do subcutâneo e da pele com náilon no 3,0 em pontos simples separados. Exame radiográfico realizado no pós-cirúrgico imediato confirmou o correto posicionamento da prótese nos canais medulares (Figura 1).

O pós-operatório constou de cloridrato de tramadol, carprofeno, dipirona e cefalexina durante 10 dias. Imobilização externa com bandagem tipo RobertJones foi mantida até o quarto dia, quando se iniciou a tentativa de caminhadas curtas, com ajuda de tipóia colocada na região abdominal do animal.

Aos 15 dias de pós-operatório, a sutura foi removida e o animal submetido à primeira sessão de quimioterapia, objetivando coibir o desenvolvimento de metástases, ainda que não-detectáveis radiograficamente, aumentando assim a sobrevida do paciente. O protocolo quimioterápico foi composto de doxorrubicina intercalado mensalmente com carboplatina, totalizando três aplicações de cada fármaco. O acompanhamento no pós-operatório incluiu radiografias do membro pélvico esquerdo e de tórax, além de exames laboratoriais constando de hemograma, função renal e hepática.

O reflexo motor do membro operado apresentou-se diminuído logo após a cirurgia, enquanto que o reflexo proprioceptivo permaneceu ausente até o sexto dia de pós-operatório. Aos 30 dias, ambos os reflexos atingiram sua normalidade, porém, foi observado decréscimo da amplitude do movimento articular. Acredita-se que a reação cicatricial e a conseqüente fibrose na região caudal à prótese reduziram a extensão máxima a $100^{\circ}$ e a flexão até $75^{\circ}$ do joelho, haja vista que antes do procedimento cirúrgico os ângulos de flexão e extensão eram normais. Apesar de tal restrição da movimentação articular, o animal utilizava o membro para apoio e sustentação de peso.

Durante o período de sobrevida, houve perda de massa muscular no membro afetado, o que pode ter impedido melhor apoio. Nas radiografias do período pós-operatório, não foram observadas 


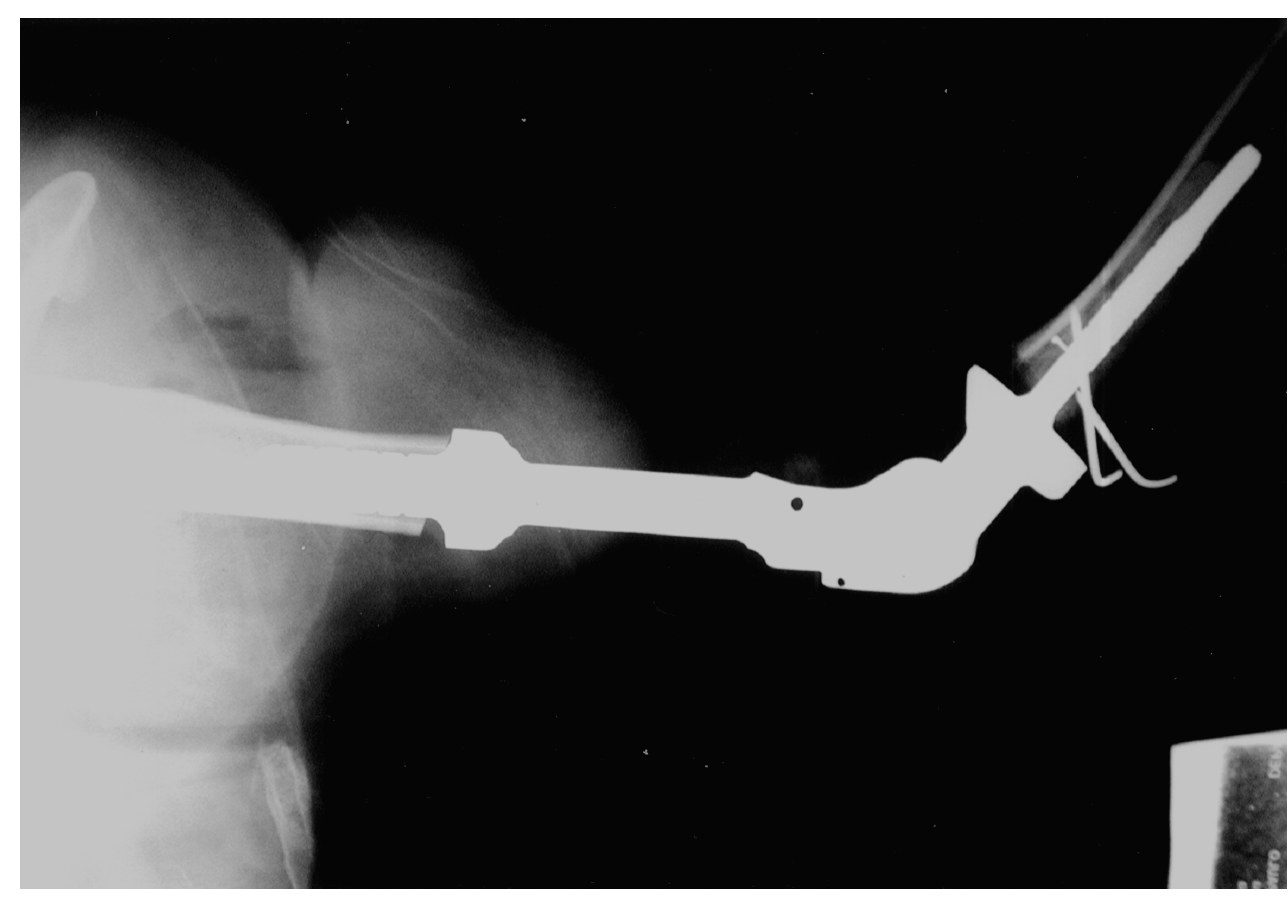

Figura 1 - Aspecto radiográfico no pós-operatório imediato da articulação fêmuro-tíbio-patelar após substituição por prótese total e articulada.

anormalidades como infecção nas adjacências da prótese ou rejeição ao implante. O cão veio a óbito após 425 dias de cirurgia por insuficiência renal crônica, sendo que a necropsia não autorizada pelo proprietário.

Em cães, próteses parciais de joelho, cimentadas ou não, são utilizadas desde 1982, em modelos experimentais (TURNER et al., 1989; BERZINS et al., 1994). Recente trabalho na literatura contempla a substituição por prótese da porção distal e diafisária do fêmur em cão com fratura de tróclea femoral (LISKA et al., 2007).

Neste relato, a superfície cartilagínea da patela foi preservada com o intuito de melhorar a adequação e o deslizamento sobre o sulco metálico da prótese. Esta técnica é comum em cirurgias de joelho em humanos, porém, os resultados clínicos são contraditórios. LINDSTRAND et al. (2001) e FURNES et al. (2002), obtiveram resultados satisfatórios em casos sem a técnica proposta, enquanto que PAKOS et al. (2005) e BERTI et al. (2006) relatam que os pacientes apresentam menos dor ao movimento do joelho quando mantida a superfície cartilagínea. No presente caso, notou-se ausência de dor à flexão do joelho, podendo significar que houve adequação da patela à prótese.

Outra preocupação aventada é quanto ao grau de inclinação do platô tibial, o que predisporia ao deslocamento cranial da tíbia em relação ao componente do fêmur (LISKA et al., 2007). Neste caso relatado, o problema foi neutralizado, visto que os componentes da prótese ficaram fixos entre si por um eixo, impedindo movimentação crânio-caudal dos elementos. As desvantagens dessa técnica são o desgaste por contato das superfícies metálicas e a liberação de partículas de metal nos tecidos moles adjacentes. Contudo, tais fenômenos não puderam ser avaliados pois o proprietário não permitiu a necropsia do animal.

O pequeno ângulo de extensão do joelho, causado pela fibrose na região articular caudal à prótese, foi fator preponderante para a dificuldade de marcha do cão. Acredita-se que esse fato esteja associado ao intervalo relativamente longo entre o ato operatório e o início da locomoção, como também a instituição tardia de um programa de reabilitação. Trabalhos mostram que, em humanos, a qualidade da marcha e a amplitude articular estão intimamente relacionados a estes fatores (MUNIN et al., 1998; NAYLOR et al., 2006).

A técnica descrita neste relato permitiu a preservação do membro em um cão após ressecção de osteossarcoma. Além disso, a técnica proporcionou junto à quimioterapia adjuvante, sobrevida relativamente longa, em se tratando de neoplasia óssea maligna. Apesar de resultados parcialmente alentadores, como utilização satisfatória do membro e 
ausência de rejeição à prótese, mais estudos devem ser conduzidos em casos clínicos de osteossarcoma na região distal de fêmur para verificação da viabilidade prática, clínica e financeira da técnica apresentada.

\section{REFERÊNCIAS}

BERTI, L. et al. Clinical and biomechanical assessment of patella resurfacing in total knee arthroplasty. Clinical Biomechanics, v.21, n.6, p.610-616, 2006.

BERZINS, A. et al. Effects of fixation technique on displacement incompatibilities at the bone-implant interface in cementless total knee replacement in a canine model. Journal of Applied Biomaterials, v.5, n.4, p.349-352, 1994.

COFONE, M.A. et al. Unilateral and bilateral stifle arthrodesis in eight dogs. Veterinary Surgery, v.21, n.4, p.299-303, 1992.

DERNELL, W.S. et al. Tumors of the skeletal system. In: WITHROW, S.J.; MACEXEN, E.G. Small animal clinical oncology. Pensilvânia: Saunders, 2001. Cap.20, p.378-417.

FURNES, O. et al. Early failures among 7,174 primary total knee replacements: a follow-up study from the Norwegian Arthroplasty Register 1994-2000. Acta Orthopaedica Scandinavica, v.73, n.2, p.117-129, 2002.
JAIN, N.B. et al. Trends in epidemiology of knee arthroplasty in the United States. Arthritis \& Rheumatism, v.52, n.12, p.3928-3933, 2005.

LINDSTRAND, A. et al. The patella in total knee arthroplasty: resurfacing or nonresurfacing of patella. Knee Surgery, Sports Traumatology, Arthroscopy, v.9, Suppl.1, p.S21-S23, 2001.

LISKA, W.D. et al. Custom total knee replacement in a dog with femoral condylar bone loss. Veterinary Surgery, v.36, n.4, p.293-301, 2007.

MUNIN, M.C. et al. Early inpatient rehabilitation after elective hip and knee arthroplasty. Journal of American Medical Association, v.279, n.11, p.847-852, 1998.

NAYLOR, J. et al. Status of physiotherapy rehabilitation after total knee replacement in Australia. Physiotherapy Research International, v.11, n.1, p.35-47, 2006

PAKOS, E.E. et al. Patellar resurfacing in total knee arthroplasty. A meta-analysis. Journal of Bone and Joint Surgery, v.87, n.7, p.1438-1445, 2005.

SUMNER, D.R. et al. Initial in vitro stability of the tibial component in a canine model of cementless total knee replacement. Journal of Biomechanics, v.27, n.7, p.929939, 1994

TURNER, T.M. et al. Bone ingrowth into the tibial component of a canine total condylar knee replacement prosthesis. Journal of Orthopaedic Research, v.7, n.6, p.893-901, 1989. 